\title{
Detection of multiple Mycoplasma species in bulk tank milk samples using real-time PCR and conventional culture and comparison of test sensitivities
}

\author{
A. Justice-Allen, ${ }^{* 1} \mathrm{~J}$. Trujillo, + G. Goodell, $\neq$ and D. Wilson* \\ *Department of Animal, Dairy, and Veterinary Science, Utah Veterinary Diagnostic Laboratory, Utah State University, Logan 84321 \\ †Center for Advanced Host Defenses, Immunobiotics and Translational Comparative Medicine, College of Veterinary Medicine, \\ lowa State University, Ames 50011 \\ ¥The Dairy Authority, Greeley, CO 80634
}

\section{ABSTRACT}

The objective of this study was to further validate a SYBR PCR protocol for Mycoplasma spp. by comparing it with standard microbial culture in the detection of Mycoplasma spp. in bulk tank milk samples. Additionally, we identified Mycoplasma spp. present by analysis of PCR-generated amplicons [dissociation (melt) temperature $\left(\mathrm{T}_{\mathrm{m}}\right)$, length, and DNA sequence]. The research presented herein tests the hypothesis that the SYBR PCR protocol is as sensitive as conventional culture for the detection of Mycoplasma spp. in bulk tank milk samples. Mycoplasmas cause several important disease syndromes in cattle, including mastitis in dairy cows. The standard diagnostic method at the herd level has been microbial isolation of mycoplasmas on 1 of several specialized media and speciation through biochemical or immunological techniques; repeated sampling schemes are recommended. The development of a real-time SYBR PCR protocol offers advantages in decrease of time to detection, cost, and complexity. The $\mathrm{T}_{\mathrm{m}}$ of the double-stranded DNA generated from the PCR reaction was used to detect the presence of and tentatively identify the species of mycoplasmas other than Mycoplasma bovis. In the SYBR PCR protocol, the presence of multiple species of mycoplasmas is indicated by an atypical dissociation curve. Gel electrophoresis and sequencing of the amplicons was used to confirm the mycoplasma species present when a non- $M$. bovis organism was detected ( $\mathrm{T}_{\mathrm{m}}$ not equal to $M$. bovis) and used to identify all the mycoplasma species present for the samples with atypical dissociation curves. Mycoplasma bovis was identified in $83 \%$ of SYBR PCR mycoplasma-positive bulk tank samples. Another mycoplasma was identified either alone or in addition to $M$. bovis in $25 \%$ of SYBR PCR mycoplasma-positive bulk tank milk samples. Four species of mycoplasma other than M. bovis (Mycoplasma alkalescens, Mycoplasma

Received October 17, 2010.

Accepted March 18, 2011.

${ }^{1}$ Corresponding author: Ajustice-allen@azgfd.gov arginini, Mycoplasma bovigenitalium, and Mycoplasma gateae) were identified in bulk tank milk samples tested with this method. Five farms had 2 mycoplasma species occurring at different times in their bulk tanks. Two mycoplasma species were identified in the same bulk tank sample in 7 instances on 2 farms. The finding of multiple Mycoplasma spp. coexisting on a farm and even in the same bulk tank milk sample indicates that the clinical significance of multiple mycoplasma species in the pathology of intramammary infections should be investigated further. In comparison with conventional culture, the SYBR PCR protocol was slightly (but not statistically significantly) more sensitive in the detection of mycoplasmas in bulk tank milk.

Key words: mycoplasma, mastitis, bulk tank milk, PCR

\section{INTRODUCTION}

Several different mycoplasmas cause mastitis in cattle and of these, Mycoplasma bovis is considered to be the most prevalent and clinically important (Jasper, 1977; González and Wilson, 2003; Ayling et al., 2004). The percentage of milk isolates of mycoplasma identified as $M$. bovis has been reported as $86 \%$ (6 of 7 positive samples) of bulk tank milk mycoplasmas in a study of the prevalence of mastitis pathogens on Prince Edward Island (Olde Riekerink et al., 2006) and in 99\% of mycoplasma-positive dairy farms in New York (González et al., 1992). However, several reports have identified other mycoplasma species (Mycoplasma bovigenitalium, Mycoplasma alkalescens, Mycoplasma canadense, strain St-6) and 2 reported dual infections (Mycoplasma californicum and $M$. canadense in both) in outbreaks of mastitis in cows (Dellinger et al., 1977; Gourlay et al., 1978; Jackson and Boughton, 1991; Infante-Martínez et al., 1999; Mackie et al., 2000). A review article published in 2003 identified 11 species of mycoplasma organisms that had been associated with outbreaks of mastitis (González and Wilson, 2003). The severity of disease appears to vary with the species involved (Jackson et al., 1981; Jackson and Boughton, 1991). Out- 
breaks of $M$. bovis and $M$. californicum have been the most serious in terms of production and animal losses (Fox et al., 2005). Historically, detection and speciation of IMI caused by mycoplasmas have used bacteriological culture for 5 to $10 \mathrm{~d}$ on selective media, followed by tests using species-specific antisera (González and Wilson, 2003; Fox et al., 2005). A nested conventional PCR protocol for detection of mycoplasmas has been developed (Baird et al., 1999). Polymerase chain reaction methods have progressed with the development of real-time protocols. The detection and identification of an individual mycoplasma species requires the use of species-specific PCR primers and use of the inappropriate primer set can result in failure to diagnose mycoplasma mastitis in the herd or individual. Previously, we reported the development of a rapid, cost-effective SYBR (an asymmetrical cyanine dye that preferentially binds to double-stranded DNA)-based real-time PCR assay that can detect and differentiate multiple species of mycoplasma in dairy cattle (Trujillo et al., 2009). The primers used in the protocol amplify the conserved region of the rRNA intergenic spacer region of the $M y$ coplasma genus. The research presented here compared the diagnostic capabilities of this real-time SYBR PCR protocol with traditional culture on bulk tank milk samples and demonstrated the ability of the protocol to detect multiple mycoplasma species and facilitate the differentiation of them from M. bovis- positive controls.

\section{MATERIALS AND METHODS}

\section{Bulk Tank Samples}

Milk samples were collected as part of a statewide surveillance program in Utah conducted by Wilson et al. (2009) in 2007. Dairy farms (designated by $\mathbf{D}$ and number) were enrolled in the testing program and bulk tank samples were collected as described previously (Wilson et al., 2009). Briefly, samples were collected by the milk haulers every 3 to $4 \mathrm{~d}$ until each tank had been sampled 5 times. Samples were frozen at $0^{\circ} \mathrm{C}$. All of the samples were transported in portable freezers to the Utah Veterinary Diagnostic Laboratory (UVDL, Logan, UT) and then shipped overnight to The Dairy Authority laboratory (TDA, Greeley, CO). The samples were then refrozen after an aliquot was removed for culturing and stored for several months. Select frozen samples were shipped back to the UVDL on frozen gel ice for SYBR PCR testing. Samples were stored at $-20^{\circ} \mathrm{C}$ for 12 to 14 months before DNA extraction and PCR testing.

\section{Mycoplasma Species Bacterial Culturing}

Mycoplasma culture was performed using $10 \mu \mathrm{L}$ of sample inoculated onto modified Hayflick medium and incubated at $37^{\circ} \mathrm{C}$ in a $10 \% \mathrm{CO}_{2}$ incubator using accepted methods (González et al., 1993). Plates were read at 3,7 , and $10 \mathrm{~d}$ by a mastitis laboratory technician with several years of experience, possessing the ability to distinguish colonies likely to be Mycoplasma spp. from those of possible contaminants such as Acholeplasma laidlawii. Plates with colonies that were morphologically consistent with those of Mycoplasma spp. were classified as positive. Final results were transmitted electronically to the UVDL.

\section{Selection of Samples for SYBR PCR}

Sixteen dairy farms had bulk tanks that cultured positive for mycoplasma organisms at least once. From this group of 16 positive farms, 165 bulk tank milk samples were selected for SYBR PCR testing for mycoplasmas. This included mycoplasma culture-negative as well as culture-positive bulk tank samples collected from those farms. In addition, 15 samples from a farm that did not have any bulk tank samples culture-positive for mycoplasma were included. The last farm was added because it had the largest number of bulk tank samples that had all been culture-negative for mycoplasma, to investigate whether the presence of mycoplasma mastitis might have been repeatedly undetected. Therefore, 17 farms were tested in the present study. The frozen samples were shipped to the UVDL overnight on cold packs. The 180 bulk tank samples were stored at $-20^{\circ} \mathrm{C}$ until testing.

\section{Sample Preparation and DNA Extraction}

The bulk tank samples were thawed at room temperature for $1 \mathrm{hr}$ and then at $4^{\circ} \mathrm{C}$ overnight. A $500-\mu \mathrm{L}$ aliquot was pelleted by centrifuging at $2,500 \times g$ for 10 min and then the DNA was extracted using an extraction kit for tissues and fluids (Qiagen, Inc., Valencia, CA). With the exception of ethanol and proteinase K, all of the buffer solutions were provided with the kit and are proprietary formulations. The milk pellet was suspended in $180 \mu \mathrm{L}$ of the tissue lysis buffer (ATL; Qiagen, Inc.) that was provided in the kit and $20 \mu \mathrm{L}$ of proteinase K. The DNA extraction process then followed the manufacturer's recommended protocol as described in Trujillo et al. (2009). The DNA was eluted from the column by washing the column twice with $100 \mu \mathrm{L}$ of $\mathrm{AE}$ (Qiagen, Inc.) buffer. The concentration of the extracted DNA ranged from 1.5 to $30 \mu \mathrm{g} /$ $\mathrm{mL}$ as determined by spectrophotometry. A positive extraction control sample of $M$. bovis [American Type Culture Collection (ATCC) \# 25025, Manassas, VA] organism in milk, and a negative extraction control of buffers only were included with each extraction group. 
The extracted nucleic acids were refrigerated for up to $3 \mathrm{~d}$ until they were used in the real-time SYBR PCR.

\section{Real-Time SYBR PCR Protocol}

The SYBR PCR reaction was performed as previously described (Trujillo et al., 2009) and included a $\mathrm{PCR}$ reaction mix volume of $12.5 \mu \mathrm{L}$, which consisted of $6.3 \mu \mathrm{L}$ of a SYBR green master mix (Quanta BioSciences, Inc., Gaithersburg, MD), a fluorescent dye that binds to double-stranded DNA during the PCR reaction; $0.5 \mu \mathrm{L}$ of each of the 2 primers (at a concentration of $2.5 \mathrm{pmol} / \mu \mathrm{L}$ ); and $5.2 \mu \mathrm{L}$ \{equivalent to $13 \mu \mathrm{L}$ of bulk tank milk $[5.2 \times(500 / 200)=13 \mu \mathrm{L}]\}$ of extracted DNA. The thermocycling conditions were the same as those described by Trujillo et al. (2009). Each PCR plate contained a PCR-positive (DNA extracted from the positive control organism described above) and -negative (DNA-free water) PCR control as well as the extraction controls. The testing for each sample was run in triplicate by combining $20.8 \mu \mathrm{L}$ of DNA with $29.2 \mu \mathrm{L}$ of SYBR green master mix and primers mixed at the above proportions and then filling each PCR reaction well with $12.5 \mu \mathrm{L}$ of sample DNA and PCR reaction master mix. Excess volume was used to provide the additional amount of reaction mixture needed for using an electronic pipette.

\section{Dissociation Curve Analysis}

The energy needed to break the base-to-base hydrogen bond of a segment of double-stranded DNA, such as a PCR amplicon, is dependent upon its length and G-C content, and when this occurs, the SYBR dye is liberated from the double-stranded DNA amplicon. This dye liberation results in a precipitous drop in fluorescence detected by the real-time PCR machine. The melt temperature $\left(\mathbf{T}_{\mathbf{m}}\right)$ of the PCR amplicon is defined as the temperature at which $50 \%$ of the doublestranded DNA becomes single stranded. A melt curve and the $\mathrm{T}_{\mathrm{m}}$ of an amplicon were determined by programming a dissociation curve following the real-time PCR and measuring the amount of fluorescence present as a function of temperature. A plot of the inverse of the first-order derivative of the change in fluorescence against time was produced. When a single amplicon is generated during PCR, a single peak is detected and the temperature at which this peak occurs is the $T_{m}$ of that amplicon. When multiple amplicons are generated, each amplicon forms a peak with a $\mathrm{T}_{\mathrm{m}}$; when the peaks overlap, a peak occurs that is broader than the peak generated by a single amplicon.

The positive control $M$. bovis DNA has a mean $\mathrm{T}_{\mathrm{m}}$ of $73.2^{\circ} \mathrm{C}$ (Trujillo et al., 2009). For each of the SYBR
PCR-positive samples, the melt curves were compared to the M. bovis-positive control included on each PCR run. The comparison included the shape as well as the identified $\mathrm{T}_{\mathrm{m}}$. Trujillo et al. (2009) demonstrated that the SYBR PCR method used here could detect the DNA of 8 different species of mycoplasma; the amplicon produced for each species was described using the $\mathrm{T}_{\mathrm{m}}$, bp length, and sequence. When a mycoplasma was detected, it was identified as either $M$. bovis or as another mycoplasma, based on the $\mathrm{T}_{\mathrm{m}}$. The identity of the species was then confirmed with post-SYBR PCR processing. When the shape of the melt curve appeared to be broader than the standard, the sample was submitted to post-SYBR PCR processing, regardless of the $\mathrm{T}_{\mathrm{m}}$.

\section{Post-SYBR PCR Processing}

All of the samples that contained a SYBR PCR product with a $\mathrm{T}_{\mathrm{m}}$ that was different than the $M$. bovis-positive control, all of the samples that were mycoplasma-positive by SYBR PCR but negative by culture, and at least 1 sample from each farm that was mycoplasma-positive both by PCR and by culture were analyzed further. The post-PCR analysis consisted of first comparing the amplicon length to the $M$. bovispositive control with a capillary electrophoresis platform (2100 Bioanalyzer; Agilent Technologies, Inc., Santa Clara, CA). When 2 distinct amplicon lengths were detected in a sample, a standard electrophoresis gel was run using a molecular-grade, low-melt agarose gel made with Tris-borate-EDTA and a nucleic acid stain (GelStar nucleic acid stain; Fisher Scientific, Inc., Pittsburgh, PA) at $100 \mathrm{~V}$ until good separation of the bands of the 100-bp ladder marker was achieved. Each DNA band was then cut from the gel and the DNA extracted for sequencing, using an extraction kit for DNA in gel (Qiagen, Inc.). Samples were sequenced on a Sanger DNA sequencing platform (3730 DNA Analyzer; Applied Biosystems, Foster City, CA) for PCR amplification products at the Center for Integrated Biosystems, Utah State University (Logan). The resulting base sequences were subjected to Basic Local Alignment Search Tool (BLAST; Zhang et al., 2000; http:// blast.ncbi.nlm.nih.gov/Blast.cgi), a search algorithm that compares a sample sequence of nucleotides or AA to sequences that have been identified and stored in the database.

\section{Statistical Analysis}

In order to determine the relative sensitivity of culture and SYBR PCR, we defined a true mycoplasmapositive bulk tank sample as any sample having at least 
Table 1. SYBR PCR and modified Hayflick medium culture results for detection of mycoplasma in 180 bulk tank milk samples ${ }^{1}$

\begin{tabular}{lccc}
\hline Item & $\begin{array}{c}\text { SYBR PCR } \\
\text { positive }\end{array}$ & $\begin{array}{c}\text { SYBR PCR } \\
\text { negative }\end{array}$ & Total \\
\hline Culture positive & 51 & 11 & 62 \\
Culture negative & 28 & 90 & 118 \\
Total & 79 & 101 & 180 \\
\hline
\end{tabular}

${ }^{1}$ All samples had 3 PCR tests; the 90 true positive cases were tested a total of 270 times by PCR. Agreement between PCR and culture methods $=141 / 180=78.3 \%(\kappa=0.54$, indicating a moderate level of agreement between tests). Specificity of both test methods $=100 \%$ by definition (no positive tests were considered false positive). Modified Hayflick medium culture test sensitivity $=62 / 90=68.9 \%$; SYBR PCR test sensitivity $=$ $207 / 270^{1}=76.7 \%$.

1 positive test, by either culture or at least 1 SYBR PCR reaction well. This case definition means that no false positives exist; thus, specificity is $100 \%$. The sensitivity of each test (culture or SYBR PCR) was then calculated by dividing the number of samples testing positive for that method (SYBR PCR or culture) by the total number of true positive samples tested. For culture, this was straightforward; the number of culture-positive tests was divided by the number of true positive samples cultured. Because 3 PCR replicates were performed on each sample, the total number of SYBR PCR wells testing positive $(0,1,2$, or 3 for each sample) was divided by the total number of wells containing a sample defined as a true positive. In order to determine the relative sensitivity of the two tests, the confidence interval was calculated as described for the method of Wilson in Thrusfield (2005; p 315) and the presence or absence of an overlap between the two was identified (Sim and Reid, 1999; Thrusfield, 2005). Agreement was also assessed with a kappa statistic (Thrusfield, 2005).

\section{RESULTS}

Sixty-two of the 180 bulk tank milk samples cultured positive for Mycoplasma spp. Of these, 51 samples were also PCR positive; 48 were PCR positive on all 3 wells, 2 were PCR positive in 2 wells, and 1 had 1 PCRpositive well (Table 1). Except for D10, all of the farms that had a positive bulk tank culture also had at least 1 mycoplasma-positive PCR test. For D10, only 1 of 19 bulk tank samples was culture-positive for mycoplasma and 19 of 19 samples were PCR-negative for mycoplasmas; the twentieth, culture-negative, sample was not available for PCR testing (the twentieth sample was not included in the statistical calculations and was not part of the 180 samples). Dairy farm 14, which did not have any mycoplasma culture-positive bulk tanks and was included as a mycoplasma culture-negative farm, had a mycoplasma-positive SYBR PCR test determined to be $M$. bovigenitalium by sequencing the amplicon.
For the remaining 11 of 62 mycoplasma culture-positive samples, mycoplasma DNA was not detected with the SYBR PCR method.

One hundred and eighteen samples were mycoplasma culture negative. Of these, 90 were also negative by SYBR PCR and, thus, classified as true negative (Table 1). However, $23.7 \%$ (28/118) of the mycoplasma culture-negative samples were positive for mycoplasma DNA by SYBR PCR. Twelve of these 28 SYBR PCR positive/culture-negative samples had 3/3 PCR-positive wells, 6 had $2 / 3$ PCR-positive wells, and 10 had 1 PCR-positive well.

Therefore, 79 samples were mycoplasma SYBR PCR positive, 51 were also mycoplasma culture positive, and 28 were culture negative. Of these SYBR PCRpositive samples, 60/79 samples were PCR-positive in $3 / 3$ wells, $8 / 79$ samples were PCR-positive in $2 / 3$ wells, and 11/79 were PCR-positive in 1 well. Based on our case definition (a sample for which a mycoplasma is detected by culture or PCR in 1 of 3 reaction wells), 90 samples were positive and 90 samples were negative.

By definition, both tests had a specificity of $100 \%$ because no positive test was considered to be a false positive. The sensitivity of culture was $62 / 90$ (68.9\%; 95\% CI 58.7 to 77.5$)$. The sensitivity of SYBR PCR was $207 / 270$ (76.7\%; $95 \%$ CI 71.3 to 81.3 ; Table 1$)$. The overlapping $95 \%$ CI indicates that the tests have a comparable sensitivity for the detection of Mycoplasma spp. in bulk tank milk. Of the 180 samples (Table 1), 141 were classified identically as either mycoplasma positive or negative by both culture and SYBR PCR for an agreement between test methods of 141/180 (78.3\%, $\kappa$ $=0.54$, moderate level of agreement; Thrusfield, 2005); 138 of the tests $(76.7 \%)$ had perfect agreement, where all 4 tests (1 culture and 3 SYBR PCR reaction wells) were identical in results (Table 1 ).

To differentiate and definitively identify the mycoplasma species detected in bulk tank samples tested, we determined the $T_{m}$, length, and DNA sequence of the PCR-generated amplicon. Based on the previously described selection criteria, $T_{m}$ different from that of the 
M. bovis-positive control (16 samples), any culture-negative/SYBR PCR-positive (15 samples), and at least 1 sample from each mycoplasma-positive farm (21 samples from 14 dairies) that had not already been selected, 52 samples were analyzed with capillary electrophoresis in order to determine the amplicon base pair length and confirm the detection of a Mycoplasma spp. (Table 2). Thirty-two samples had a $\mathrm{T}_{\mathrm{m}}$ that was the same as the M. bovis-positive control; these consisted of the 14 of 15 culture-negative/SYBR PCR-positive samples, and 18 of the 21 samples from mycoplasma-positive farms. One of the 15 culture-negative samples was identified by analysis of the SYBR PCR $\mathrm{T}_{\mathrm{m}}$, amplicon length, and amplicon DNA sequence as $M$. bovigenitalium $\left(\mathrm{T}_{\mathrm{m}}\right.$ $=73.18^{\circ} \mathrm{C}$ and $222 \mathrm{bp}$ compared to $M$. bovis $\mathrm{T}_{\mathrm{m}}=$ $73.39^{\circ} \mathrm{C}$ and $\left.207 \mathrm{bp}\right)$. In all, 16 samples with a $\mathrm{T}_{\mathrm{m}}$ that was different from that of the $M$. bovis-positive control (range of $\mathrm{T}_{\mathrm{m}}$ from 71.6 to $73.2^{\circ} \mathrm{C}$ ) were identified; 4 of these were culture-negative for mycoplasma and 12 were mycoplasma culture-positive. Three samples (from 1 positive farm) had a $T_{m}$ that was the same as the positive control and had amplicons of two different lengths (Figure 1), one that matched M. bovis and one that was identified as a second mycoplasma species $(M$. alkalescens in 2 samples and $M$. gateae in 1 sample). The $\mathrm{T}_{\mathrm{m}}$ of samples with a mycoplasma other than $M$. bovis tended to be lower than the $\mathrm{T}_{\mathrm{m}}$ of samples with $M$. bovis plus another species (Table 3). In total, $M$. bovis was identified in 39 of 52 (75\%) SYBR PCR-positive samples analyzed with electrophoresis; in $7(18 \%$ of $M$. bovis-positive samples) of those samples, another mycoplasma was detected.

Twenty samples (25\% of all SYBR PCR-positive samples) had a $\mathrm{T}_{\mathrm{m}}$ that was lower than the M. bovispositive control and an amplicon that was different in length from the $M$. bovis-positive control; 4 of those samples had amplicons of 2 distinct lengths, indicating more than 1 species of mycoplasma in the same sample. The SYBR PCR products from these 4 samples were additionally analyzed with a low-melt agarose gel electrophoresis from which the DNA of each band of SYBR PCR product was then extracted separately and sequenced (Figure 1). Sequencing of the PCR product from all 20 samples confirmed the presence of mycoplasmas that were different from M. bovis (GenBank accession number AY566217.1) and the presence of more than 1 mycoplasma species in 7 bulk tanks of those 20 bulk tanks (Table 2). The other mycoplasma species identified by sequencing and comparison were $M$. alkalescens ( $\mathrm{n}=13$, GenBank accession number AY816348.1), M. arginini ( $\mathrm{n}=4$, GenBank accession number AY737013.1), M. bovigenitalium ( $\mathrm{n}=1$, GenBank accession number AY780797.1), and M. gateae
( $\mathrm{n}=2$, GenBank accession number DQ847420.1). The 7 bulk tanks with 2 species of mycoplasma all had $M$. bovis with another mycoplasma ( $M$. alkalescens in $5, M$. gateae in 1, and $M$. arginini in 1). Five dairies had bulk tanks that tested negative, positive, and then negative for mycoplasma at different times during the sampling protocol.

\section{DISCUSSION}

The SYBR PCR protocol described was comparable to conventional microbial culture in the detection of Mycoplasma spp. in bulk tank milk samples, as illustrated by the nearly $80 \%$ agreement between test methods. However, the SYBR PCR assay is capable of concurrently differentiating some of the Mycoplasma spp. present. In addition, the sensitivities of the 2 tests were not significantly different. These results are consistent with previous studies using a nested conventional PCR method (Baird et al., 1999). A real-time PCR method like the one described here requires fewer reagents and is less subject to technical error and contamination than conventional nested PCR methods (Cai et al., 2005). While PCR costs more per test than conventional culture (approximately $\$ 20.00$ vs. 6.00 ), PCR has the advantage of a faster turnaround time (2 vs. 10 d). A shorter turnaround time would be advantageous when attempting to remove mycoplasma-positive cows from a herd. This data demonstrates that the SYBR PCR assay can accurately detect Mycoplasma spp. in bulk tank samples collected from a field study. Moreover, using these field samples, we were able to facilitate the differentiation of mycoplasma species among Mycoplasma-positive samples. Three mycoplasma spp. (M. alkalescens, M. arginini, and $M$. bovigenitalium) were detected and identified in addition to $M$. bovis. A fourth mycoplasma species could not be definitively identified; the sequence of the amplicon matched the sequences of $M$. gateae, $M$. canadense, and $M$. arginini equally. Mycoplasma californicum was not isolated in this study.

Given the ability of PCR to detect the nucleic acid signature of nonviable organisms, it is not surprising that $24 \%$ of the mycoplasma culture-negative samples were positive for mycoplasma using the SYBR PCR. In addition, Mycoplasma spp. can be difficult to cultivate in the laboratory because of special growth requirements, overgrowth by other bacteria, or if low numbers of organisms are present in the tested sample. It is also not unexpected that more variability was found in the PCR replicates for the SYBR PCR-positive, culturenegative samples (some had only 2 positive reaction wells out of 3 and others had only 1 positive well out 
Table 2. Amplicon length and DNA sequence results for SYBR PCR-positive samples

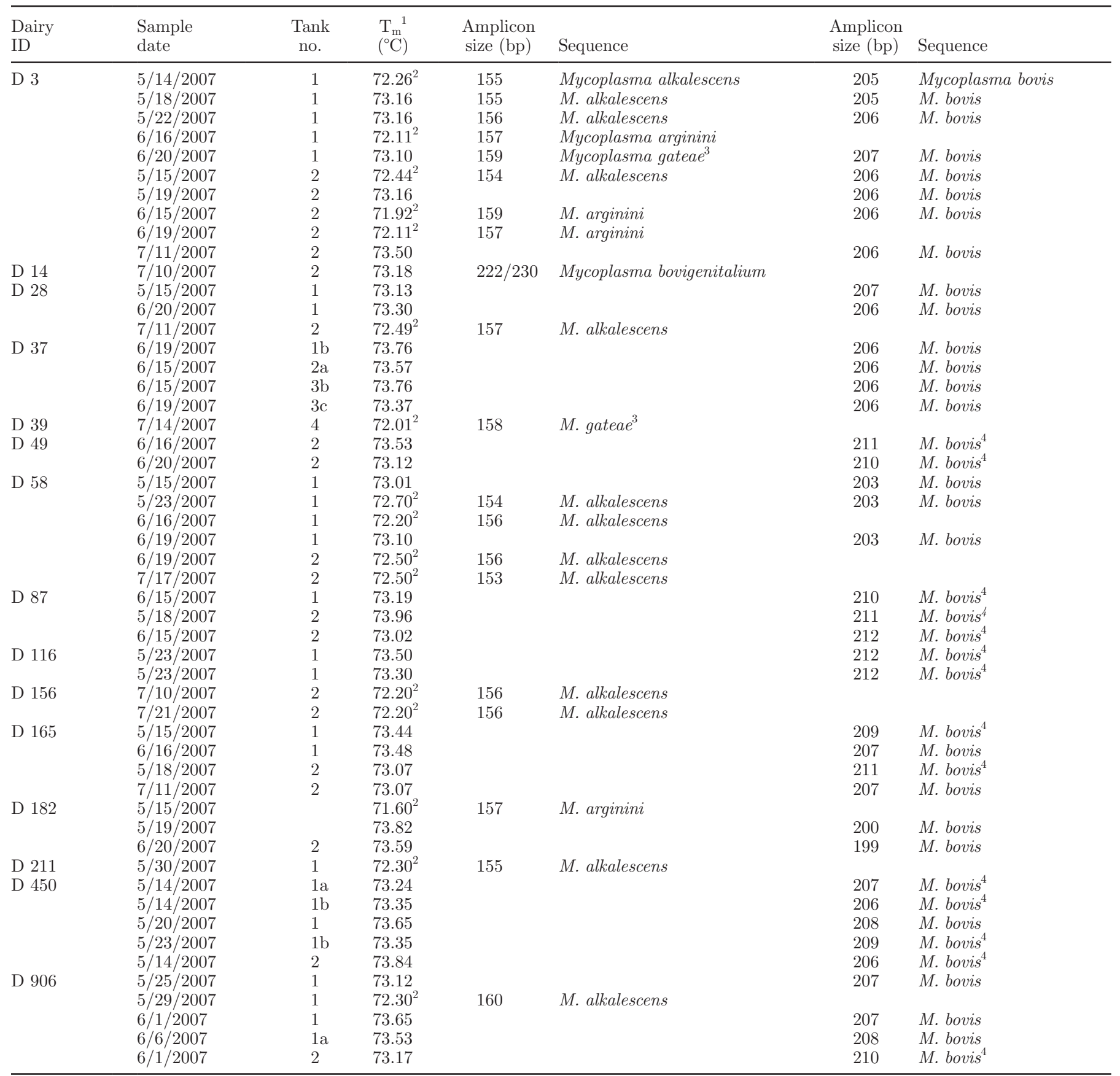

\footnotetext{
${ }^{1}$ Melt temperature, the temperature at which double-stranded DNA disassociates into single strands.

${ }^{2} \mathrm{~T}_{\mathrm{m}}$ different from that of $M$. bovis-positive control, $\mathrm{n}=16$.

${ }^{3}$ Sequence also matches Mycoplasma canadense and M. arginini (see Table 4)

${ }^{4}$ Species determined by amplicon length matching $M$. bovis-positive control.
}

of 3) because these culture-negative samples may have had a lower concentration of mycoplasma DNA or partially degraded DNA from nonviable organisms.

Three possible explanations exist for lack of detection of mycoplasma DNA with SYBR PCR in some of the culture-positive samples. First, the milk samples went through 2 freeze/thaw cycles between culturing and PCR testing. This has been shown to decrease the detection by PCR by $1 \log _{10}$ for each cycle through the loss of pathogen-specific DNA (Biddle et al., 2004; 
Table 3. Mean melt temperature $\left(\mathrm{T}_{\mathrm{m}}\right)^{1}$ and mean amplicon lengths of Mycoplasma spp. identified in bulk tank milk samples using SYBR PCR and electrophoresis and used to tentatively differentiate Mycoplasma spp. detected

\begin{tabular}{lcccc}
\hline Species & $\begin{array}{c}\text { Mean } \mathrm{T}_{\mathrm{m}} \\
\left({ }^{\circ} \mathrm{C}\right)\end{array}$ & $99 \% \mathrm{CI}$ & $\begin{array}{c}\text { Mean amplicon } \\
\text { length (bp) }\end{array}$ & $99 \%$ CI \\
\hline Mycoplasma bovis & 73.39 & $73.26-73.52$ & 207.3 & $205.7-208.9$ \\
Mixed species $_{\text {Non-bovis positive }}^{2}$ & 72.67 & $72.15-73.19$ & & \\
Mycoplasma bovigenitalium $^{2}$ & 72.12 & $71.92-72.32$ & 156.5 & $155.1-157.9$ \\
\hline
\end{tabular}

${ }^{1}$ The temperature at which double-stranded DNA disassociates into single strands.

${ }^{2}$ Except for the one identified as M. bovigenitalium.

Cai et al., 2005). Second, length of storage can affect the number of viable organisms; an increase of approximately $20 \%$ in culture-negative samples with a storage period of $4 \mathrm{wk}$ at $-20^{\circ} \mathrm{C}$ was found in one study (Biddle et al., 2004). A decrease in the number of viable organisms would be expected to be accompanied by a decrease in the quality of the DNA. Additionally, milk has been a notoriously difficult sample (Hotzel et al., 1999) to work with for PCR purposes and initial attempts were unsuccessful (Hirose et al., 2001). The presence of PCR inhibitors or the adverse effect of the lipid content of milk on nucleic extraction protocols could have decreased the sensitivity of the SYBR PCR. Both the lipid content and the concentration of inhibitors vary in milk in general and in mastitic milk specifically. For samples with low numbers of organisms and small amounts of DNA, these processes, freezing, inhibitors, and lipids, could have affected the detection rate of the

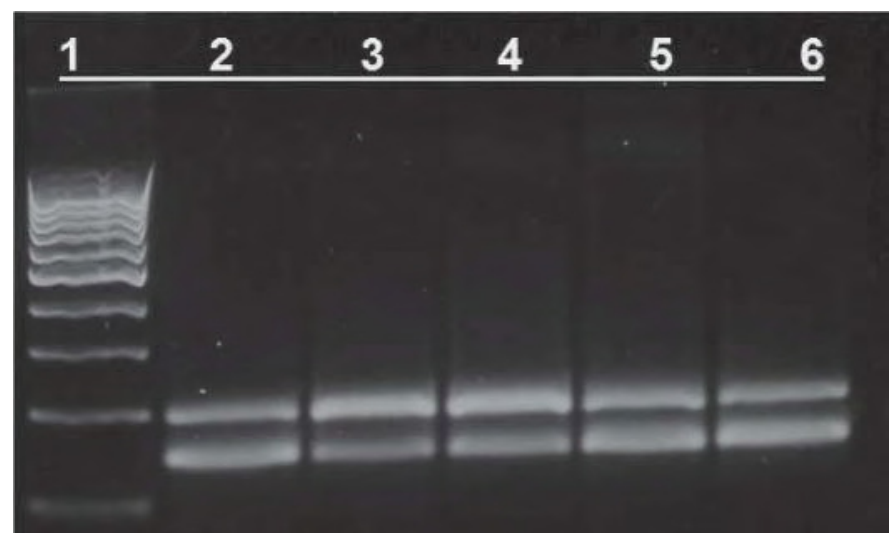

Figure 1. Representative electrophoresis image of bulk tank milk samples from dairy 3 with 2 different amplicons detecting 2 different species of mycoplasma concurrently. Lanes are as follows: (1) 100-bp ladder (reference for amplicon size); (2) T1, 5/14/07 (tank number, date), a 155-bp amplicon (Mycoplasma alkalescens) and a 205-bp amplicon (Mycoplasma bovis); (3) T1, 5/18/07, a 155-bp amplicon (M. alkalescens) and a 205-bp amplicon (M. bovis); (4) T1, 5/22/07, a 156-bp amplicon (M. alkalescens) and a 206-bp amplicon (M. bovis); (5) T1, 6/20/07, a 159-bp amplicon (Mycoplasma gateae) and a 207bp amplicon ( $M$. bovis); and (6) T2, 5/15/07, a 154-bp amplicon ( $M$. alkalescens) and a 206-bp amplicon (M. bovis).
SYBR PCR. One way to detect the presence of inhibitors is to use a duplex PCR protocol with an internal positive control. Future research should address this question.

Consistent with previous studies, several farms had bulk tank samples that alternated from negative to positive and back over the extended sampling period (González and Wilson, 2003; Fox et al., 2005). This finding previously has been attributed to the intermittent shedding of organisms by infected cows (Biddle et al., 2003; Wilson et al., 2007). This observation was repeated again in this study with 2 separate detection methods, conventional culture and SYBR PCR, thus reinforcing the recommendation that multiple bulk tank samples over time are necessary to rule out mycoplasma infection within a herd.

Using field samples we were able to detect and differentiate additional mycoplasma species among $M y$ coplasma bovis-positive samples. Some of the species detected are not surprising, as they have been associated with previous outbreaks of mastitis or have been detected in earlier survey studies (Jackson et al., 1981; Kirk et al., 1997; Mackie et al., 2000). For 2 samples, the small PCR-generated amplicon matched equally well with $M$. gateae, $M$. canadense, and $M$. arginini (Table 4). The sequences of $M$. gateae, M. alkalescens, and $M$. arginini are highly similar (95 to $97 \%$ ) in the intergenic spacer region (Zhang et al., 2000; BLAST/ GenBank). Mycoplasma gateae was first identified and characterized by physiological and immunogenic methods (Cole et al., 1967). Since then there have been 5 additional reports of the isolation of $M$. gateae from 4 clinical samples from cats or dogs and 1 survey of normal cats. Three were from cats with arthritis, conjunctivitis, or keratitis and 1 was from a dog coinfected with canine distemper virus (Tan et al., 1977; Rosendal, 1978; Moise et al., 1983; Gray et al. 2005; Zeugswetter et al., 2007). Mycoplasma gateae could be a contaminant. Many dairy farms have populations of feral and domestic cats and organisms shed from these animals could be pulled into the bulk tank with the air from the milking parlor or could come from the 
Table 4. A comparison of the amplicon sequence from two dairy farms (D3 and D39) with the corresponding sequence from 3 Mycoplasma spp. demonstrating a base pair mismatch between the amplicon sequence and the species sequence at bp 5 (bold) of the amplicon

\begin{tabular}{|c|c|c|}
\hline $\begin{array}{l}\text { Mycoplasma canadense } \\
\text { Mycoplasma arginini } \\
\text { Mycoplasma gateae } \\
\text { Amplicon D3 and D39 }\end{array}$ & $\begin{array}{l}\text {---AAAGTTTAGATCAACCTATAGAATATATCATACAATAGACAAACAAT } \\
\text {---AAAGTTTAGATCAACCTATAGAATATATCATACAATAGACAAACAAT } \\
\text {---AAAGTTTAGATCAACCTATAGAATATATCATACAATAGACAAACAAT } \\
\text { AAAACGTTTAGATCAACCTATAGAATATATCATACAATAGACAAACAAT }\end{array}$ & $\begin{array}{l}47 \\
47 \\
47 \\
50\end{array}$ \\
\hline $\begin{array}{l}\text { M. canadense } \\
\text { M. arginini } \\
\text { M. gateae } \\
\text { Amplicon D3 and D39 }\end{array}$ & $\begin{array}{l}\text { AGGTCTTATACTACTATTAAACAAGATAAGAGTTTTTGGTGGATGC---- } \\
\text { AGGTCTTATACTACTATTAAACAAGATAAGAGTTTTTGGTGGATGC---- } \\
\text { AGGTCTTATACTACTATTAAACAAGATAAGAGTTTTTGGTGGATGC--- } \\
\text { AGGTCTTATACTACTATTAAACAAGATAAGAGTTTTTGGTGGATGCAATA }\end{array}$ & $\begin{array}{r}93 \\
93 \\
93 \\
100\end{array}$ \\
\hline
\end{tabular}

${ }^{1}$ M. canadense strain $275 \mathrm{c}$.

${ }^{2} M$. gateae strain KDC.

teat skin of milking cows. Additionally, not all of the Mycoplasma spp. isolated from domestic animals have been associated with disease (Tan et al., 1977; Razin et al., 1998); for bovines, M. gateae could be a commensal organism. Alternatively, this mycoplasma species could be playing a role in mastitis, which would warrant further investigation.

The other Mycoplasma spp. detected and differentiated following employment of the SYBR PCR assay in the present study, M. alkalescens, $M$. arginini, and $M$. bovigenitalium, have been documented as the cause of disease in cattle (González and Wilson, 2003; Fox et al., 2005 ) and the ability to detect them with or without concurrent $M$. bovis detection could prove important clinically.

The results of this study have implications for our understanding of mycoplasma mastitis at the herd level. The research presented here definitively identified $M$. bovis in $49 \%$ of the SYBR PCR-positive samples with electrophoresis of the amplicon; 27 (34\%) samples not analyzed with electrophoresis were most likely M. bovis, based on the melt curve and $\mathrm{T}_{\mathrm{m}}$ analysis, resulting in a prevalence for $M$. bovis in bulk tank milk samples of 83\%. Another mycoplasma species was identified alone or accompanied by $M$. bovis in $25 \%$ of the samples. While $M$. bovis is still the predominant mycoplasma identified, this is somewhat lower than $M$. bovis prevalence rates identified in other studies (González et al., 1992; Kirk et al., 1997; Ayling et al., 2004; Olde Riekerink et al., 2006). The dairy farms from which the mycoplasmas were detected all had clinical evidence of disease based on the survey completed in a previous study, and 9 of the farms that elected to do individual cow testing during the subsequent year as a follow up to the bulk tank identification detected the disease in individual cows in their herds (Wilson et al., 2009). The occurrence of mixed mycoplasma outbreaks has been documented (Mackie et al., 2000; González and Wilson, 2003) and multiple species of mycoplasmas can be isolated from normal and pneumonic calves (Thomas et al., 2002; Marques et al., 2007). However, the frequency of the simultaneous occurrence of multiple species of mycoplasmas on farms that are not experiencing an outbreak of mycoplasma mastitis is unknown. One other study (Kirk et al., 1997) identified multiple Mycoplasma spp. in bulk tank milk samples; in addition to $M$. bovis, M. alkalescens, $M$. bovigenitalium, $M$. californicum, and $M$. canadense, nonpathogenic species of mycoplasma were isolated. Generally, in both disease surveillance and in outbreak investigations, the object has been the identification of the presence of mycoplasma organisms and not speciation. This is due, in part, to the difficulty, expense, and time involved in speciating the organisms via immunological methods (González and Wilson, 2003; Fox et al., 2005). In addition, when the causative organism is speciated, in approximately $90 \%$ of the cases $M$. bovis is identified (González et al., 1992, Kirk et al., 1997; Ayling et al., 2004; Olde Riekerink et al., 2006). There could also be a perception that the species of mycoplasma associated with mastitis or other diseases of adult dairy cows is not clinically relevant. However, the duration of infection and the long and short term effects on production appear to vary with the mycoplasma species identified (González and Wilson, 2003; Jackson et al., 1981). The clinical relevance of the identification of multiple species of mycoplasmas in a single dairy herd should be investigated further. This new SYBR PCR assay can be used as a tool to facilitate the diagnosis of mycoplasma infections in cattle, facilitate the differentiation of the species of mycoplasma present, and study the role of Mycoplasma spp. other than M. bovis as primary or secondary pathogens in dairy cattle.

\section{ACKNOWLEDGMENTS}

This research was made possible through a grant from the American Association of Bovine Practitioners. 
We also thank the milk buyers, the milk plant staff, and cooperating dairy producers for providing the samples. In addition, the contributions from the staff at the Utah Veterinary Diagnostic and the Dairy Authority Laboratories were invaluable. Thanks to Maria Hansen for her help with the processing of the samples.

\section{REFERENCES}

Ayling, R. D., S. E. Bashiruddin, and R. A. Nicholas. 2004. Mycoplasma species and related organisms isolated from ruminants in Britain between 1990 and 2000. Vet. Rec. 155:413-416.

Baird, S. C. . J. Carman, R. P. Dinsmore, R. L. Walker, and J. K. Collins. 1999. Detection and identification of Mycoplasma from bovine mastitis infections using a nested polymerase chain reaction. J. Vet. Diagn. Invest. 11:432-435.

Biddle, M. K., L. K. Fox, and D. D. Hancock. 2003. Patterns of mycoplasma shedding in the milk of dairy cows with intramammary mycoplasma infection. J. Am. Vet. Med. Assoc. 223:1163-1166.

Biddle, M. K., L. K. Fox, D. D. Hancock, C. T. Gaskins, and M. A Evans. 2004. Effects of storage time and thawing methods on the recovery of Mycoplasma species in milk samples from cows. J. Dairy Sci. 87:933-936.

Cai, H. Y., P. Bell-Rogers, L. Parker, and J. F. Prescott. 2005. Development of a real-time PCR for detection of Mycoplasma bovis in bovine milk and lung samples. J. Vet. Diagn. Invest. 17:537-545.

Cole, B. C., L. Golightly, and J. R. Ward. 1967. Characterization of Mycoplasma strains from cats. J. Bacteriol. 94:1451-1458.

Dellinger, J. D., D. E. Jasper, and M. Ilić. 1977. Characterization studies on mycoplasmas isolated from bovine mastitis and the bovine respiratory tract. Cornell Vet. 67:351-360.

Fox, L. K., J. H. Kirk, and A. Britten. 2005. Mycoplasma mastitis: A review of transmission and control. J. Vet. Med. B Infect. Dis. Vet. Public Health 52:153-160.

González, R. N., B. M. Jayarao, S. P. Oliver, and P. M. Sears. 1993. Pneumonia, arthritis, and mastitis in dairy cows due to $\mathrm{Myco-}$ plasma bovis. Pages 178-186 in Proc. 32nd Annual Meeting of the National Mastitis Council. Natl. Mastitis Counc., Madison, WI.

González, R. N., P. M. Sears, R. A. Merrill, and G. L. Hayes. 1992. Mastitis due to Mycoplasma in the state of New York during the period 1972-1990. Cornell Vet. 82:29-40.

González, R. N., and D. J. Wilson. 2003. Mycoplasmal mastitis in dairy herds. Vet. Clin. North Am. Food Anim. Pract. 19:199-221.

Gourlay, R. N., S. G. Wyld, N. F. Burke, and M. J. Edmonds. 1978. Isolation of Mycoplasma canadense from an outbreak of bovine mastitis in England. Vet. Rec. 103:74-75.

Gray, L. D., K. L. Ketring, and Y. W. Tang. 2005. Clinical use of $16 \mathrm{~S}$ rRNA gene sequencing to identify Mycoplasma felis and $M$. gateae associated with feline ulcerative keratitis. J. Clin. Microbiol. 43:3431-3434.

Hirose, K., Y. Kawasaki, K. Kotani, A. Tanaka, K. Abiko, and H. Ogawa. 2001. Detection of mycoplasma in mastitic milk by PCR analysis and culture method. J. Vet. Med. Sci. 63:691-693.

Hotzel, H., M. Heller, and K. Sachse. 1999. Enhancement of Mycoplasma bovis detection in milk samples by antigen capture prior to PCR. Mol. Cell. Probes 13:175-178.

Infante-Martínez, F., J. Aguado, and D. Eduard-Jasper. 1999. Mastitis outbreak due to Mycoplasma californicum and Mycoplasma canadense in a commercial dairy herd in the state of Jalisco, México. Rev. Latinoam. Microbiol. 41:117-120.
Jackson, G., and E. Boughton. 1991. A mild outbreak of bovine mastitis associated with Mycoplasma bovigenitalium. Vet. Rec. 129:444-446.

Jackson, G., E. Boughton, and S. G. Hamer. 1981. An outbreak of bovine mastitis associated with Mycoplasma canadense. Vet. Rec. 108:31-32.

Jasper, D. E. 1977. Mycoplasma and mycoplasma mastitis. J. Am. Vet. Med. Assoc. 170:1167-1172.

Kirk, J. H., K. Glenn, L. Ruiz, and E. Smith. 1997. Epidemiologic analysis of Mycoplasma spp. isolated from bulk-tank milk samples obtained from dairy herds that were members of a milk cooperative. J. Am. Vet. Med. Assoc. 211:1036-1038.

Mackie, D. P., D. Finlay, N. Brice, and H. J. Ball. 2000. Mixed mycoplasma mastitis outbreak in a dairy herd. Vet. Rec. 147:335-336.

Marques, L. M., M. Buzinhani, R. C. Oliveira, M. Yamaguti, J. B. Ferreira, R. L. Neto, and J. Timenetsky. 2007. Prevalence of mycoplasmas in the respiratory tracts of calves in Brazil. Vet. Rec. 161:699-700.

Moise, N. S., J. W. Crissman, J. F. Fairbrother, and C. Baldwin. 1983. Mycoplasma gateae arthritis and tenosynovitis in cats: Case report and experimental reproduction of the disease. Am. J. Vet. Res. 44:16-21.

Olde Riekerink, R. G. M., H. W. Barkema, S. Veenstra, D. E. Poole, R. T. Dingwell, and G. P. Keefe. 2006. Prevalence of contagious mastitis pathogens in bulk tank milk in Prince Edward Island. Can. Vet. J. 47:567-572.

Razin, S., D. Yogev, and Y. Naot. 1998. Molecular biology and pathogenicity of mycoplasmas. Microbiol. Mol. Biol. Rev. 62:1094-1156.

Rosendal, S. 1978. Canine mycoplasmas: Pathogenicity of mycoplasmas associated with distemper pneumonia. J. Infect. Dis. 138:203-210.

Sim, J., and N. Reid. 1999. Statistical inference by confidence intervals: Issues of interpretation and utilization. Phys. Ther. 79:186-195.

Tan, R. J., E. W. Lim, and B. Ishak. 1977. Ecology of mycoplasmas in clinically healthy cats. Aust. Vet. J. 53:515-518.

Thomas, A., H. Ball, I. Dizier, A. Trolin, C. Bell, J. Mainil, and A. Linden. 2002. Isolation of Mycoplasma species from the lower respiratory tract of healthy cattle and cattle with respiratory disease in Belgium. Vet. Rec. 151:472-476.

Thrusfield, M. 2005. Veterinary Epidemiology. Blackwell Publishing Professional, Ames, IA.

Trujillo, J., A. Justice-Allen, T. Morley, and D. Wilson. 2009. SYBR green real-time PCR detection and differentiation assay for $\mathrm{Myco-}$ plasma species in biological samples. Page 97 in Proc. of the Am. Assoc. Vet. Lab. Diag., San Diego, CA. University of California, Davis, CA

Wilson, D. J., G. Goodell, A. Justice-Allen, and S. T. Smith. 2009 Herd-level prevalence of Mycoplasma spp. mastitis and characteristics of infected dairy herds in Utah as determined by a statewide survey. J. Am. Vet. Med. Assoc. 235:749-754.

Wilson, D. J., R. T. Skirpstunas, J. D. Trujillo, K. B. Cavender, C. V. Bagley, and R. L. Harding. 2007. Unusual history and initial clinical signs of Mycoplasma bovis mastitis and arthritis in firstlactation cows in a closed commercial dairy herd. J. Am. Vet. Med. Assoc. 230:1519-1523.

Zeugswetter, F., K. M. Hittmair, A. G. de Arespacochaga, S. Shibly, and J. Spergser. 2007. Erosive polyarthritis associated with Mycoplasma gateae in a cat. J. Feline Med. Surg. 9:226-231.

Zhang, Z., S. Schwartz, L. Wagner, and W. Miller. 2000. A greedy algorithm for aligning DNA sequences. J. Comput. Biol. 7:203-214. 